\title{
苂Fermilab
}

Dinesertorate

\section{MEMORANDUM OF UNDERSTANDING}

FOR THE 2010 FERMILAB TEST BEAM FACILITY PROGRAM

\section{T-1008}

SuperB Muon Detector Prototype

November 15, 2010

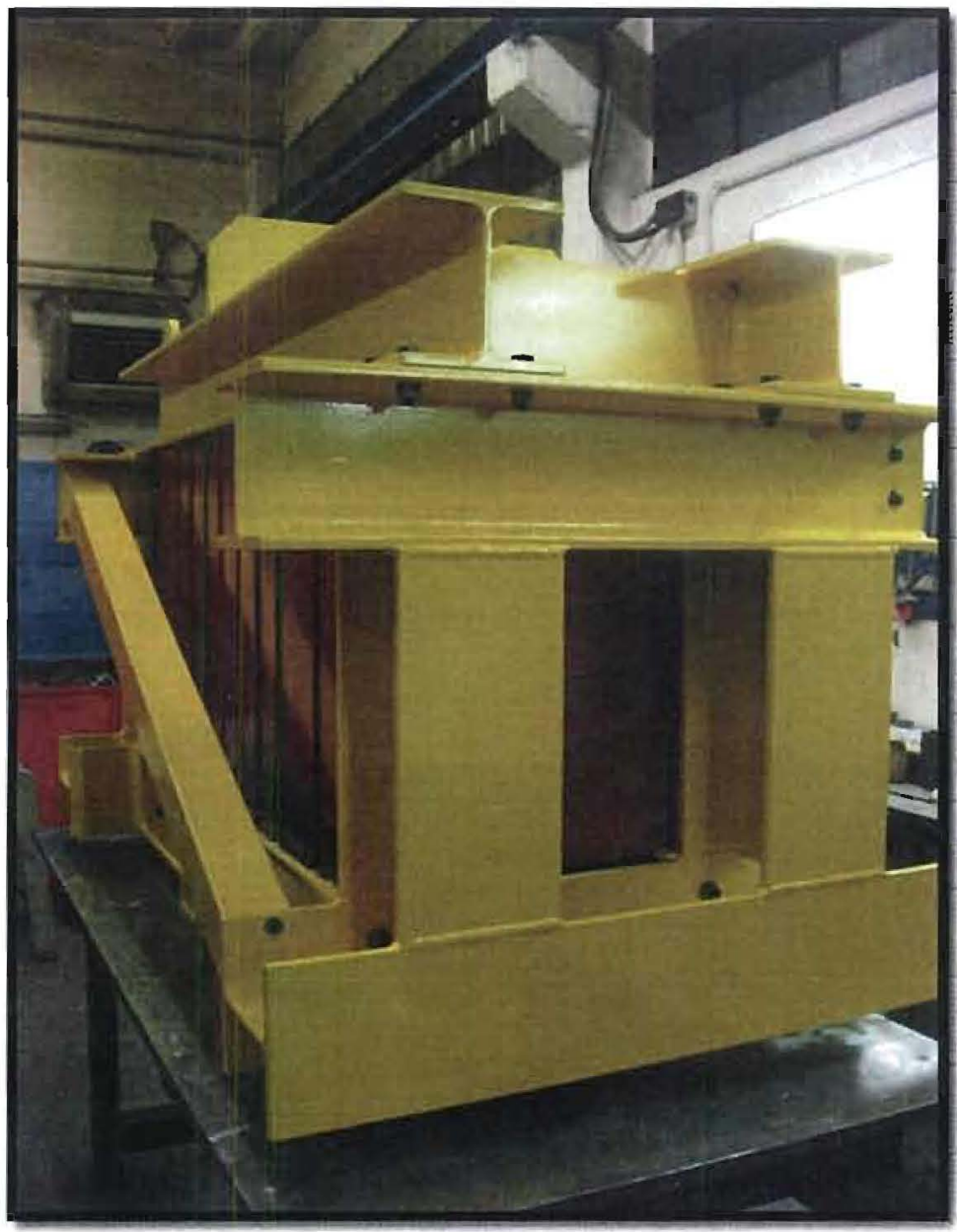




\section{TABLE OF CONTENTS}

INTRODUCTION

1. PERSONNEL AND INSTITUTIONS 4

2. EXPERIMENTAl AREA, BeAms AND SCHEdule Considerations 5

3. RESPONSIBILITIES BY INSTITUTION - NON FERMILAB 8

4. RESPONSIBILITIES BY INSTITUTION - FERMILAB 9

4.1. Fermilab ACCElerator Division 9

4.2. Fermilab Particle Physics Division 9

4.3. Fermilab Computing Division 9

4.4. FERMILAB ES\&H SECTION 10

5. Summary OF COSTS 11

$\begin{array}{ll}\text { 6. Special Considerations } & 12\end{array}$

$\begin{array}{ll}\text { SignATURES } & 14\end{array}$

$\begin{array}{ll}\text { APPENDIX I - MT6 AREA LAYOUT } & 15\end{array}$

$\begin{array}{ll}\text { APPENDIX II - EQUIPTMENT NEEDS } & 16\end{array}$

APPENDIX III - HAZARD IDENTIFICATION CHECKLIST 


\section{INTRODUCTION}

This is a memorandum of understanding between the Fermi National Accelerator Laboratory (Fermilab) and the experimenters of INFN Ferrara and INFN Padova who have committed to participate in beam tests to be carried out during the 2010 Fermilab Test Beam Facility program.

The memorandum is intended solely for the purpose of recording expectations for budget estimates and work allocations for Fermilab, the funding agencies and the participating institutions. It reflects an arrangement that currently is satisfactory to the parties; however, it is recognized and anticipated that changing circumstances of the evolving research program will necessitate revisions. The parties agree to modify this memorandum to reflect such required adjustments. Actual contractual obligations will be set forth in separate documents.

\section{Description of Detector and Tests:}

The test objective is to optimize the muon identification in an experiment at a Super B Factory. To accomplish this, experimenters will study the muon identification capability of a detector with different iron configurations at different beam energies.

The detector is a full scale prototype, composed of a stack of iron tiles. The segmentation of the iron allows the study of different configurations. Between the tiles, one or two extruded scintillator slabs can be inserted to test two different readout options; a Binary Readout and a Time Readout. In the Binary Readout option the two coordinates are given by the two orthogonal scintillator bars, and the spatial resolution is driven by the bar width. In the Time Readout option one coordinate is determined by the scintillator position and the other by the arrival time of the signal read with a TDC. 


\section{Experimental Area, Beams ANd Schedule Considerations:}

\subsection{LOCATION}

\subsubsection{BEAMLINE}

The experiment is to take place in the MTest beamline and will be situated in the MT6.2 enclosure. The apparatus is expected to be located in the $\mathrm{C}$ area. To obtain the very lowest beam energies the experimenters may wish to utilize the tertiary beamline in this enclosure, in which case the detector may be moved horizontally over a few feet during the course of the tests.

\subsubsection{ADDITIONAL}

Some space in the Meson Detector Building high-bay is needed for storing the detector (approximately $57 " \mathrm{H} \times 67$ ' $\mathrm{L} \times 40$ "w) between it's arrival at Fermilab from Italy and its installation in the beam area.

\section{2. $\underline{\text { BEAM }}$}

\subsubsection{BEAM TYPES AND INTENSITIES}

Energy of beam: $1-5 \mathrm{GeV}$

Particles: muons and pions

Intensity: $0.1 \mathrm{k}-1 \mathrm{k}$ particles/spill

Beam spot size: about $10 \mathrm{~cm}^{2}$

The experimenters will need at least $1000 \mathrm{mu} / \mathrm{pi}$ per spill for 4, and 5 and maybe $6 \mathrm{GeV}$ momentum particles. The lower momentums would be appreciated, but not crucial to the completion of the experiment. This request is unique as the experimenters are asking for momentum tagged muons at low momentum, rather than just "straight-thrus". The bulk of this effort falls on the PPD FTBF Group to provide Cherenkov and TOF for particle identification. It is likely the beam tuning will require inserting lead in the beam to reduce electrons. A remote lead piece for this purpose exists, and all parties are agreeable on its use. It's also likely that if FTBF is successful in tagging, it will require Accelerator Division to push the intensity limits. A best effort to meet the above requirements will be made.

\subsubsection{BEAM SHARING}

Due to the size and density of the detector sharing would most likely not be possible. The beam parameters are such that other users would most likely not be interested in sharing

\subsection{EXPERIMENTAL CONDITIONS}

\subsubsection{APPARATUS}

The detector is a full scale prototype composed of a stack of iron tiles with a total depth of 92 $\mathrm{cm}$; its segmentation allows the study of different configurations. The gaps, with an area of 


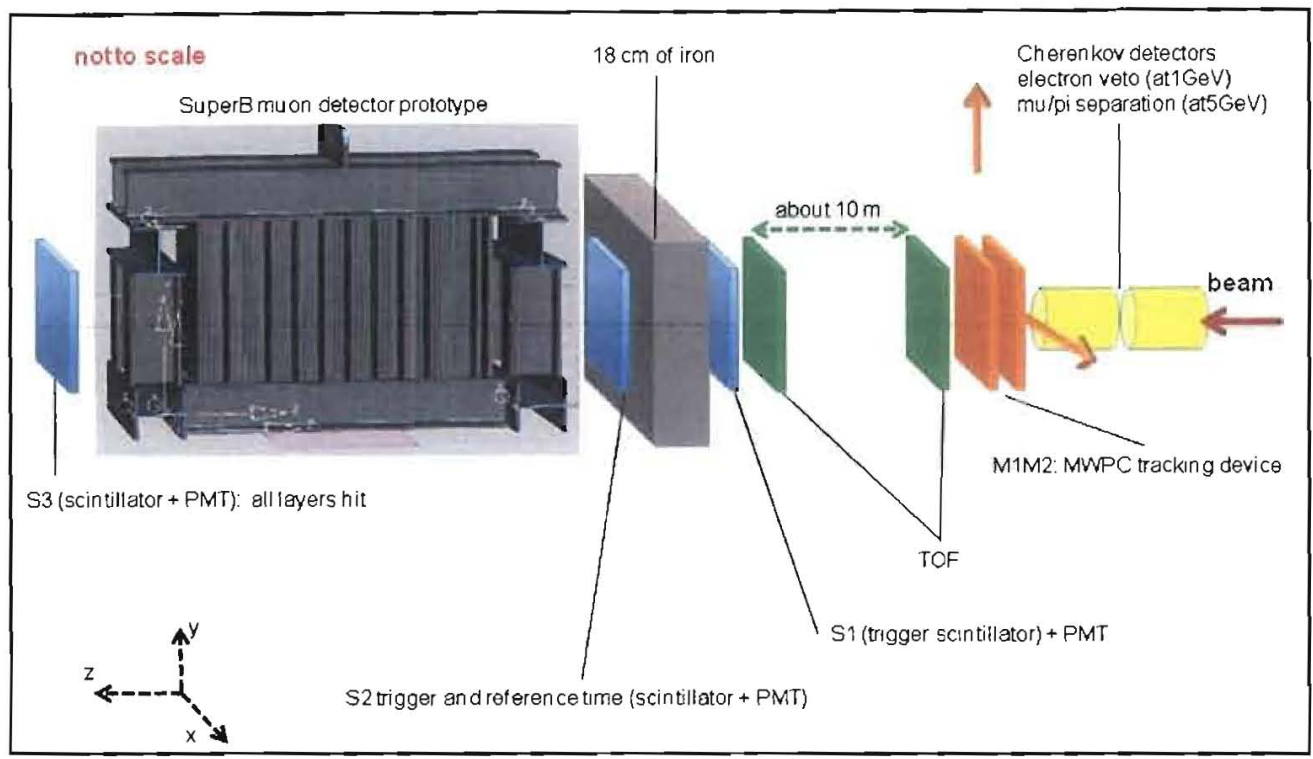

\subsubsection{ELECTRONICS NEEDS}

Each scintillator plane is assembled in a light-tightened box which also contains fibers, photodetectors and fiber-SiPM coupling PCB's. Signals from PCB's are wired to a custom-made crate with size comparable to the standard VME crate for amplification, discrimination and Binary readout. Discriminated signals from time readout modules are then routed to a standard VME crate equipped with two TDC's for the time measurements. Binary and TDC data are sent separately to the DAQ system via TCP/IP connection, therefore a network connection between the experimental hall and the counting room is necessary.

DAQ system consists of a dedicated PC that operates as RUN control and Online monitor. The $\mathrm{PC}$ is equipped with Linus-CERN operating system and the DAQ application is $\mathrm{C}++$ based.

\subsubsection{DESCRIPTION OF TESTS}

The main objective is to study the muon identification capability with different iron configurations. In order to change configurations a limited number of accesses are needed. Tests are performed with different beam energies, as listed above. To obtain the very lowest beam energies the experimenters may wish to utilize the tertiary beamline in this enclosure.

\subsection{SCHEDULE}

The two scintillator layout options will be tested at the same time by equipping some gaps with the first one and some with the second one. With this set-up the tests can be accomplished in a 7 day time slot (Dec 1 - Dec 7) with the week before available for installation and beamless tests.

The experiment may return at a later date to explore momentum below $1 \mathrm{GeV}$ with the tertiary beamline. 


\section{RESPONSIBILITIES BY INSTITUTION - FERMILAB}

\subsection{FERMILAB ACCELERATOR DIVISION:}

4.1.1. Use of MTest beamline as outlined in Section II.

4.1.2. Maintenance of all existing standard beam line elements (SWICs, loss monitors, etc) instrumentation, controls, clock distribution, and power supplies.

4.1.3. Scalers and beam counter signals should be made available in the counting house.

4.1.4. Reasonable access to the equipment in the MTest beamline.

4.1.5. Connection to beams control console and remote logging (ACNET) should be made available.

4.1.6. The test beam energy and beam line elements will be under the control of the AD Operations Department Main Control Room (MCR).

4.1.7. Position and focus of the beam on the experimental devices under test will be under control of MCR. Control of secondary devices that provide these functions may be delegated to the experimenters as long as it does not violate the Shielding Assessment or provide potential for significant equipment damage.

4.1.8. The integrated effect of running this and other SY120 beams will not reduce the antiproton stacking rate and the neutrino flux by more than $5 \%$ globally, with the details of scheduling to be worked out between the experimenters and the Office of Program Planning.

\subsection{FERMILAB PARTICLE PHYSICS DIVISION:}

4.2.1. The test-beam efforts in this MOU will make use of the Fermilab Test Beam Facility. Requirements for the beam and user facilities are given in Section II. The Fermilab Particle Physics Division will be responsible for coordinating overall activities in the MTest beam-line, including use of the user beam-line controls, readout of the beam-line detectors, and FTBF computers. [0.5 person weeks]

4.2.2. Set up and maintenance of the Time of Flight system. [0.5 person weeks]

4.2.3. Set up and maintenance of the MWPC tracking system (2 stations). [0.5 person weeks]

4.2.4. Set up and maintenance of 3 scintillator counters with PMTs. [0.25 person weeks]

4.2.5. Set up and maintenance of the Cherenkov particle ID system. In order to reject the huge amount of electrons in the beam at such low momentum, one Cherenkov detector will be operated as electron veto. The other Cherenkov counter will be filled with $\mathrm{C} 4 \mathrm{~F} 8 \mathrm{O}$ gas to give muon/pion separation for particles with momentum starting from about $2.2 \mathrm{GeV}$. Muon/pion identification below $2.2 \mathrm{GeV}$ will be handled by means of a time of flight device with few ps resolution over a lever arm of 10 meters. The setup of PID devices is responsibility of the Fermilab Particle Physics Division while the C4F8O gas will be purchased by the user institutions. [0.5 person weeks]

4.2.6. Support only for FTBF DAQ systems as needed.

4.2.7. Crane Operation for installation. [1 person weeks] 


\section{MOU for T-1008 SuperB Muon Detector Prototype}

\section{SUMMARY OF COSTS}

\begin{tabular}{|l|c|c|c|}
\hline Source of Funds [\$K] & Equipment & Operating & $\begin{array}{c}\text { Personnel } \\
\text { (person-weeks) }\end{array}$ \\
\hline Particle Physics Division & $\$ 0 \mathrm{~K}$ & $\$ 0 \mathrm{~K}$ & 3.75 \\
\hline Accelerator Division & $\frac{0}{0}$ & 0 & 0.5 \\
\hline Computing Division & & 0 & 0 \\
\hline & $\$ 0 \mathrm{~K}$ & $\$ 0 \mathrm{~K}$ & 4.25 \\
\hline Totals Fermilab & & & \\
\hline Totals Non-Fermilab & & \\
\hline
\end{tabular}




\section{MOU for T-1008 SuperB Muon Detector Prototype}

6.8.3. The experimenters will assist the Fermilab Divisions and Sections with the disposition of any articles left in the offices they occupied.

6.9. An experimenter will be available to report on the test beam effort at a Fermilab All Experimenters' Meeting. 


\section{SIGNATURES:}
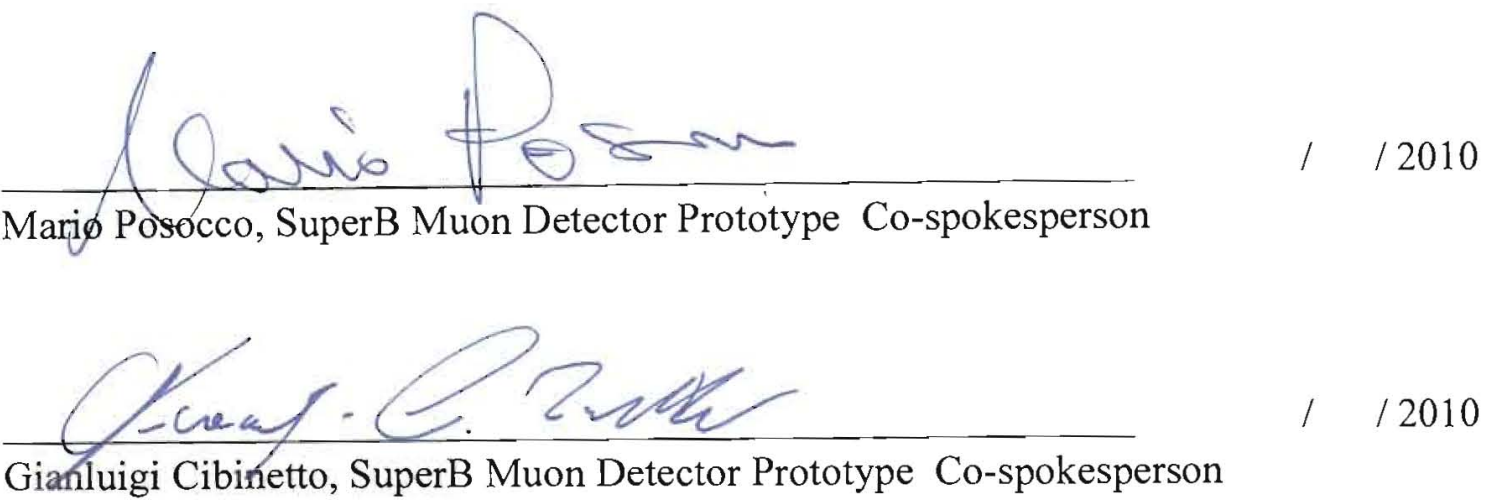

Gianluigi Cibinetto, SuperB Muon Detector Prototype Co-spokesperson

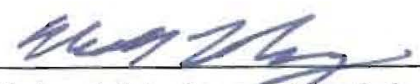

/1 //6/2010

Michael Lindgref, Particle Physics Division

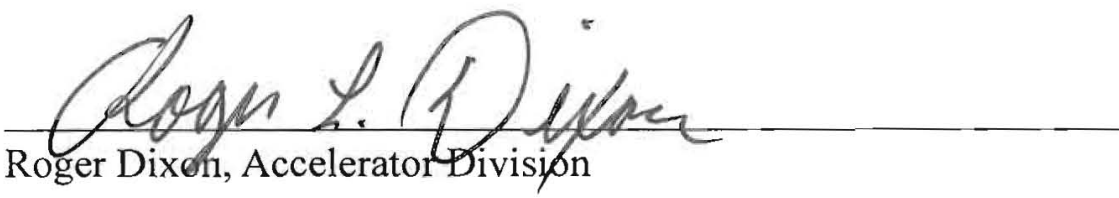

\section{Pele Coope}

$1 / / 16 / 2010$

Peter Cooper, Computing Division

Imantha muchies for

$/ / / 16 / 2010$

Nancy Grossman, ES\&H Section

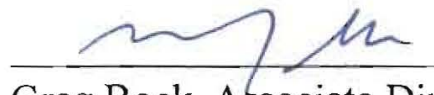

Greg Bock, Associate Director for Research, Fermilab

$11 / 23 / 2010$

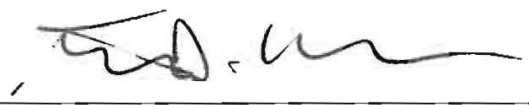

$1 /, 19,2010$

Stuart Henderson, Associate Director for Accelerators, Fermilab 


\section{APPENDIX I: MT6 AREA LAYOUT}

Experiment will set up in the MT6.2-B and C areas.

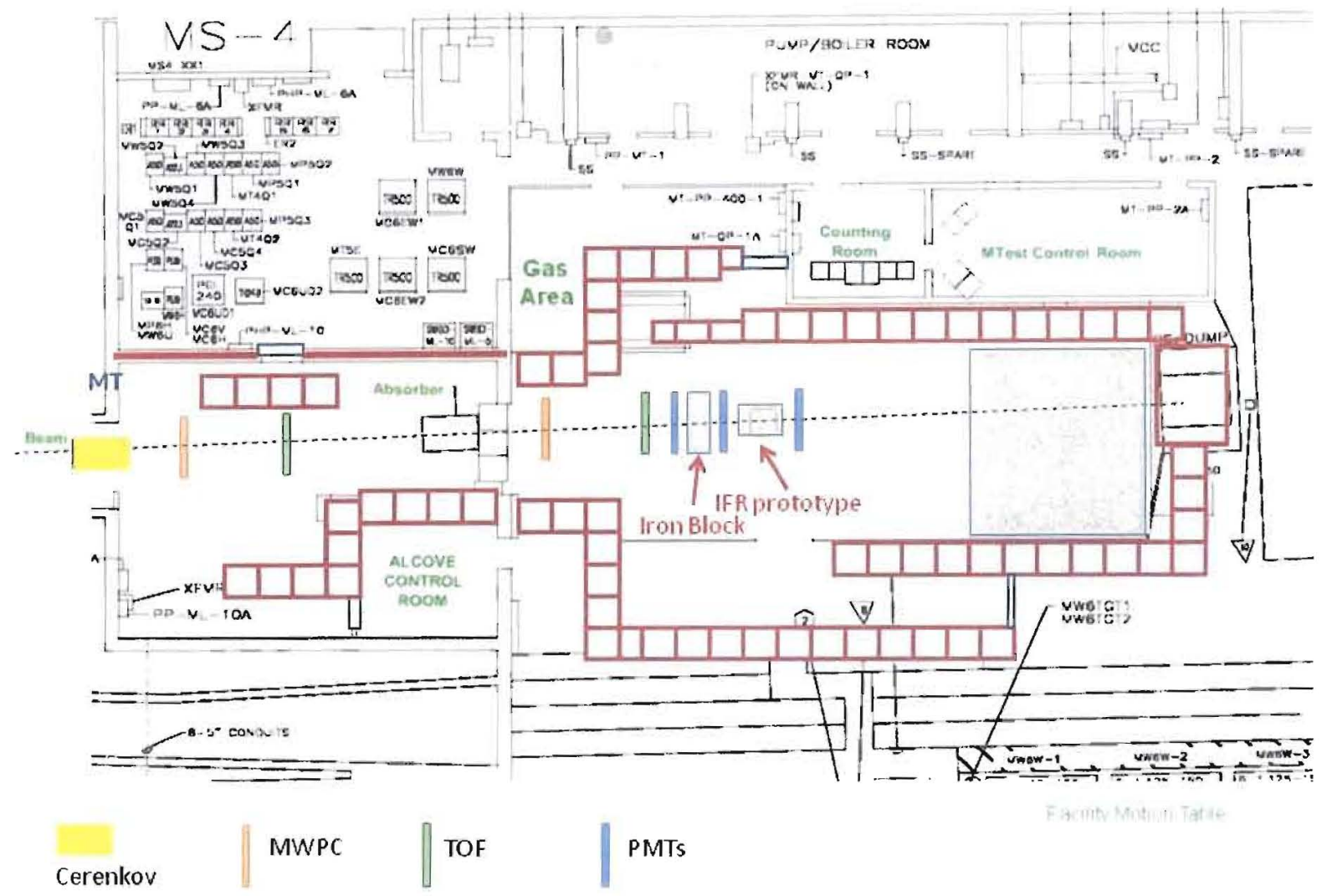

Equipment in the enclosure includes:

- An aluminum box, containing the fibers for the binary readout measuring $140 \mathrm{~cm} \times 60$ $\mathrm{cm} \times 3 \mathrm{~cm}$.

- The mechanical structure has an overall length of $1.5 \mathrm{~m}$, a width of $1.0 \mathrm{~m}$ (1.6 m taking into account the scintillator plane boxes) and a height of $0.8 \mathrm{~m}$.

- An iron absorber block, $18 \mathrm{~cm}$ x $30 \mathrm{~cm}$ x $30 \mathrm{~cm}$

The total weight is 4.0 tons. 


\section{APPENDIX II: EQUIPMENT NEEDS}

Equipment Pool and PPD items needed from Fermilab, on the first day of setup.

\section{Quantity Description}

PREP EQUIPMENT POOL:

1 crate CAMAC

1 crate NIM

1 module NIM Fan Out/ Fan In Mod. LeCroy 428F (or equivalent)

1 module NIM Coincidence Unit Mod. LeCroy 465 (or equivalent)

1 module NIM NIM-ECL level translator Mod. LeCroy 4616 (or equiv.)

1 module NIM discriminator Mod. 623B (or equivalent)

1 Low Voltage power supply 0-24V

? cables, power cords, adapters etc. (to be defined)

\section{PPD FTBF:}

scintillator paddles (complete with PMTs) to be used as a trigger/time reference (possibly 12 " x 12" or bigger)

$1 \quad$ HV power supply for the above scintillators

$2 \quad$ Cerenkov counters

$2 \quad$ MWPC Tracking stations

? Lemo cables, various lengths (to be defined)

1 Iron absorber appr. $30 \mathrm{~cm} \times 30 \mathrm{~cm} \times 18 \mathrm{~cm}$ to be put before the detector

1 A suitable support table, movable if needed for installation, able to hold the detector aligned with the beam 


\section{APPENDIX III: - HAZARD IDENTIFICATION CHECKLIST}

Items for which there is anticipated need have been checked.

\begin{tabular}{|c|c|c|c|c|c|}
\hline \multicolumn{2}{|c|}{ Cryogenics } & \multicolumn{2}{|c|}{ Electrical Equipment } & \multicolumn{2}{|c|}{ Flammable Gases or Liquids } \\
\hline \multicolumn{2}{|c|}{ Beam line magnets } & \multicolumn{2}{|c|}{ Cryo/Electrical devices } & \multicolumn{2}{|l|}{ Type: } \\
\hline \multicolumn{2}{|c|}{ Analysis magnets } & \multicolumn{2}{|c|}{ capacitor banks } & Flow rate: & \\
\hline \multicolumn{2}{|c|}{ Target } & \multicolumn{2}{|c|}{ high voltage } & Capacity: & \\
\hline \multicolumn{2}{|c|}{ Bubble chamber } & \multicolumn{2}{|c|}{ exposed equipment over $50 \mathrm{~V}$} & \multicolumn{2}{|c|}{$\begin{array}{c}\text { Hazardous/Toxic } \\
\text { Materials }\end{array}$} \\
\hline \multicolumn{2}{|c|}{ Pressure Vessels } & \multicolumn{2}{|c|}{ Other Gas Emissions } & \multicolumn{2}{|c|}{$\begin{array}{l}\text { List hazardous/toxic materials planned for } \\
\text { use in a beam line or experimental } \\
\text { enclosure: }\end{array}$} \\
\hline & inside diameter & Type: & $\mathrm{C} 4 \mathrm{~F} 8 \mathrm{O}$ & & \\
\hline & operating pressure & Flow rate: & $140 \mathrm{lbs} /$ week & & \\
\hline & window material & Capacity: & $140 \mathrm{lbs}$ & & \\
\hline & window thickness & \multicolumn{2}{|c|}{ Radioactive Sources } & & \\
\hline \multicolumn{2}{|c|}{ Vacuum Vessels } & \multicolumn{2}{|c|}{ permanent installation } & \multicolumn{2}{|c|}{ Target Materials } \\
\hline & inside diameter & \multicolumn{2}{|c|}{ temporary use } & \multicolumn{2}{|c|}{ Beryllium (Be) } \\
\hline & operating pressure & \multicolumn{2}{|l|}{ Type: } & \multicolumn{2}{|c|}{ Lithium (Li) } \\
\hline & window material & \multicolumn{2}{|l|}{ Strength: } & \multicolumn{2}{|c|}{ Mercury $(\mathrm{Hg})$} \\
\hline & window thickness & \multicolumn{2}{|c|}{ Hazardous Chemicals } & \multicolumn{2}{|c|}{ Lead $(\mathrm{Pb})$} \\
\hline & Lasers & Cyar & de plating materials & & $\operatorname{sten}(W)$ \\
\hline Per & ent installation & Scint & Ilation Oil & & $\operatorname{um}(U)$ \\
\hline Ten & ary installation & $\mathrm{PCB}$ & & $\mathrm{X}$ & Iron $(\mathrm{Fe})$ \\
\hline Cal & & Meth & & Me & anical Structures \\
\hline Ali & & TMA & & & g devices \\
\hline type: & & TEA & & & on controllers - manual \\
\hline Wattage: & & phot & graphic developers & $x$ & iding/elevated platforns \\
\hline class: & & Othe & Activated Water? & & \\
\hline
\end{tabular}

